\title{
Phase II assessment of talabostat and cisplatin in second-line stage IV melanoma
}

\author{
Robert M Eager1,11, C Casey Cunningham¹, Neil N Senzer1,2,3,4, \\ Joe Stephenson Jr ${ }^{5}$, Stephen P Anthony ${ }^{6}$, Steven J O'Day ${ }^{7}$, Gary Frenette ${ }^{8}$, \\ Anna C Pavlick 9 , Barry Jones ${ }^{10}$, Margaret Uprichard ${ }^{10}$ and \\ John Nemunaitis*1,2,3,4
}

\begin{abstract}
Address: ${ }^{1}$ Mary Crowley Cancer Research Centers, Dallas, TX, USA, ${ }^{2}$ Texas Oncology PA, Dallas, TX, USA, ${ }^{3}$ Baylor Sammons Cancer Center, Dallas, TX, USA, ${ }^{4}$ Gradalis, Inc., Dallas, TX, USA, ${ }^{5}$ Clinical Research Unit, Cancer Centers of the Carolinas, Greenville, SC, USA, ${ }^{6}$ Cancer Care Northwest, Spokane, WA, USA, ${ }^{7}$ The Angeles Clinic and Research Institute, Los Angeles, CA, USA, ${ }^{8}$ Carolinas Medical Center, Charlotte, NC, USA,

'Department of Dermatology, New York University Clinical Cancer Center, New York, NY, USA, ${ }^{10}$ Point Therapeutics, Inc., Boston, MA, USA and ${ }^{11}$ Department of Internal Medicine, The University of Hawaii, Honolulu, HI, USA

Email: Robert M Eager - eager.rm@gmail.com; C Casey Cunningham - ccunningham@terapio.com; Neil N Senzer - NSenzer@marycrowley.org; Joe Stephenson - Joe.Stephenson@USOncology.com; Stephen P Anthony - stephen.anthony@usoncology.com;

Steven J O'Day - soday@theangelesclinic.org; Gary Frenette - gfrenette@carolinas.org; Anna C Pavlick - anna.pavlick@nyumc.org;

Barry Jones - bjones@ziopharm.com; Margaret Uprichard - muprichard@epixpharma.com; John Nemunaitis* - JNemunaitis@marycrowley.org

* Corresponding author
\end{abstract}

Published: 30 July 2009

BMC Cancer 2009, 9:263 doi:10.1/86/147|-2407-9-263
Received: 31 December 2008

Accepted: 30 July 2009

This article is available from: http://www.biomedcentral.com/I47I-2407/9/263

(C) 2009 Eager et al; licensee BioMed Central Ltd.

This is an Open Access article distributed under the terms of the Creative Commons Attribution License (http://creativecommons.org/licenses/by/2.0), which permits unrestricted use, distribution, and reproduction in any medium, provided the original work is properly cited.

\begin{abstract}
Background: Metastatic melanoma is an incurable disease with an average survival of less than one year. Talabostat is a novel dipeptidyl peptidase inhibitor with immunostimulatory properties.

Methods: This phase II, open label, single arm study was conducted to evaluate the safety and efficacy of $75-100 \mathrm{mg} / \mathrm{m}^{2}$ cisplatin combined with $300-400 \mathrm{mcg}$ talabostat bid for 6,21 -day cycles. The primary endpoint was overall response. The rate of complete responses, duration of overall objective response, progression-free survival (PFS), and overall survival were the secondary endpoints.
\end{abstract}

Results: Six objective partial responses were recorded in the 74 patients $(8.1 \%)$ in the intentionto-treat population. Five of these responses involved the 40 evaluable patients (I2.5\%). Thirty-one percent of patients reported SAEs to the combination of talabostat and cisplatin.

Conclusion: Acceptable tolerability was observed in the intention-to-treat population and antitumor activity was observed in $12.5 \%$ of evaluable patients, which is not greater than historical expectation with cisplatin alone.

\section{Background}

Therapeutic options for advanced melanoma are limited to palliative management. No treatments have demonstrated survival advantage once metastatic lesions develop. Combination therapy produces the highest response rates, but overall survival remains less than 12 months. The combination chemotherapy of cisplatin/vinblastine/dacarbazine produces a response rate of $40 \%$ and a median overall survival of 9 months [1]. The regimen of cisplatin/dacarbazine/carmustine with or without 
tamoxifen results in a $15-52 \%$ response rate and median survival of 6.8-10.8 months [2-4]. The addition of the biochemotherapeutic agents, interferon-alpha (IFN- $\alpha$ ) or interleukin-2 (IL-2), separately or in combination, produces a modest improvement in response rate, but without survival benefit [5-13] and with increased toxicity. Single-agent treatment has similarly failed to significantly improve survival; agents that have been used include dacarbazine [14], temozolomide [15], cisplatin [16], and nitrosoureas $[15,17]$.

Talabostat (valine-proline-boronic acid) together with other amino boronic dipeptides was originally designed as a high affinity, competitive inhibitor of the enzyme dipeptidyl peptidase IV (DPP-IV or CD26) [18]. The compound was found to stimulate hematopoiesis and antitumor immune responses via cytokine upregulation [1921]. In addition to DPP-IV, the dipeptidyl peptidases 8 and 9 (DPP-8 and DPP-9) and fibroblast activation protein (FAP) were subsequently shown to be sensitive to inhibition by talabostat $[22,23]$. Based on similarities of protein structure and substrate specificity, DPPs- 8 and -9 and FAP are classified as members of the DPP-IV-like family of post-prolyl cleaving serine proteases [24].

DPPs- 8 and -9 are cytosolic proteases and their inhibition by talabostat has been shown to cause caspase- 1 activation and IL-1 $\beta$ induction in macrophages, which in turn causes upregulation of the cytokines and chemokines that characterize the responses to talabostat, both in vitro and in tumor-bearing mice [23]. FAP has previously been described as a type II membrane protein with dipeptidyl peptidase and gelatinase activity (reviewed in [24]). Studies of FAP have reported that FAP expression is induced in fibroblasts associated with the stroma of malignant epithelial tumors and healing wounds [25-27]. These reports suggest that FAP does not appear to be expressed constitutively in most healthy tissues of the adult animal; although FAP expression in bone marrow and lymphoid tissue from both healthy and tumor-bearing mice has been demonstrated [22]. FAP, therefore, represents a molecular target for talabostat in tumor stroma; but the involvement of FAP in the antitumor effects of talabostat in mouse tumor models is currently unclear.

The biological activities of the cytokines and chemokines upregulated by talabostat suggest that both innate and adaptive immunity are evoked. In animal models, talabostat enhanced the production of cytokines in tumor tissue and lymphoid organs, resulting in enhanced tumorspecific T-cell-dependent [19] and T-cell-independent $[20,21]$ immunity. These antitumor responses were enhanced by concomitant treatment with chemotherapeutic agents, including cisplatin, gemcitabine, paclitaxel, 5-fluorouracil, and the monoclonal antibody rituximab
[21]. The mechanism underlying the synergistic effects is unknown; but it may involve the exposure of tumor antigens by chemotherapy-induced cellular apoptosis in tumor models in immunocompetent mice [28].

Clinical studies have shown talabostat to be well tolerated [29-31]. In a phase I trial in thirteen patients treated concomitantly with immunosuppressive chemotherapy, five patients showed improvement in grade 3 neutropenia and most developed elevations in serum cytokine levels [29]. A phase I trial of talabostat and rituximab in rituximabresistant lymphoma showed cytokine elevations in most patients with partial response in 3 patients [31]. However, a phase II trial of talabostat in metastatic colorectal carcinoma reported no objective responses [32].

The cooperative or synergistic interactions observed with cisplatin and dacarbazine are particularly relevant to the investigation of the activity of talabostat in metastatic melanoma. In mouse models of WEHI 164 and EL4 tumors, the combination treatment of established tumors with talabostat and cisplatin revealed a significantly enhanced antitumor effect compared with either agent alone [20]. Mice rendered tumor-free following treatment with talabostat and cisplatin were resistant to rechallenge with tumors cells of the primary type, suggesting the development of therapy-based immune protection. Based on these findings, we investigated the effects of talabostat in combination with cisplatin in patients with metastatic melanoma.

\section{Methods \\ Patient Population}

Patients were eligible for inclusion if they were 18 years or older with histologically or cytologically confirmed metastatic melanoma, Stage IV according to the AJCC [33], with measurable disease per Response Evaluation Criteria in Solid Tumors (RECIST) with at least one measurable index lesion with clearly defined margins documented by spiral computed tomography (CT) or magnetic resonance imaging (MRI). Color medical photograph for skin and oral lesions or plain X-ray also were done to evaluate presence of disease. A radiated lesion was be considered an index lesion unless there was evidence of disease progression at that site prior to first administration of study medication. Additional inclusion criteria were Eastern Cooperative Oncology Group (ECOG) performance status of 0,1 , or 2 ; and an expected survival of $\geq 12$ weeks. Patients with previously irradiated and/or resected asymptomatic central nervous system (CNS) metastases were eligible for the study.

Patients were excluded from study participation if they had received more than one prior chemotherapy or immunotherapy regimen for Stage IV melanoma, or radi- 
ation therapy to $>50 \%$ of the pelvis. Patients were also excluded from the study if they had clinically significant abnormalities in laboratory tests for hepatic, biliary, renal or hematological function, per normal laboratory parameters. Additional factors disqualifying a potential patient included the following: symptomatic CNS metastases with or without significant edema; $<3$ weeks since prior focused radiotherapy for brain metastases or $<4$ weeks since prior whole brain radiotherapy; the need for chronic (i.e., $>7$ days) oral or intravenous (IV) corticosteroid therapy with $>10 \mathrm{mg} /$ day prednisone equivalents; any comorbidity or condition which, in the opinion of the investigator, interfered with the assessments and procedures of the protocol; or any malignancy within the 5 years immediately prior to the first dose of study medication with the exception of basal cell or non-metastatic squamous cell carcinoma of the skin and carcinoma in situ of the cervix. Patients were also excluded if they were within 30 days of surgery, chemotherapy, radiation therapy, immunotherapy, or other investigational medication for melanoma; patients must have recovered from all of the side effects of treatment in order to be enrolled. Women were excluded if they were pregnant or lactating. Women of childbearing potential and non-vasectomized men agreed to use a barrier method of contraception during treatment.

\section{Study Design}

This was a Phase II open-label, single-arm, multicenter study designed to enroll up to 54 evaluable patients, with 19 evaluable patients to be enrolled into Stage 1 (safety assessment) of the study. Upon satisfactory evaluation of safety and initial evidence of antitumor activity, an additional 35 evaluable patients were enrolled. Patients received combination therapy with cisplatin and Talabostat.

The dose of cisplatin was $100 \mathrm{mg} / \mathrm{m}^{2}$ administered intravenously on Day 1 of each 21-day cycle for 6 cycles.

Talabostat 300 mcg was administered orally twice daily (BID) from Days 2 through 15 of Cycle 1. In Cycle 2 or subsequent cycles, the talabostat dose could be increased to $400 \mathrm{mcg}$ BID depending on tolerability. Patients received study treatment in 21-day cycles for up to 6 cycles. If cisplatin was discontinued for toxicity talabostat could be continued for subsequent cycles as single agent.

All patients were to be followed for progressive disease (PD) and/or survival for up to 12 months following their last dose of talabostat, unless another anti-melanoma treatment was initiated.

The study was conducted in accordance with current US Food and Drug Administration (FDA) regulations, good clinical practice (GCP), the International Conference on Harmonisation (ICH) guidelines, the version of the Declaration of Helsinki current at the time of the study, and local ethical and legal requirements. Informed consent was signed by each patient prior to his or her participation in the study.

\section{Study Objectives}

The primary objective was to determine objective response rate, defined as the proportion of evaluable patients who achieved a complete response (CR) or partial response (PR) per RECIST. Objective response was determined using an imaging technique (e.g. CT, MRI) including all index lesions. Confirmation of response was to be documented by repeat imaging no sooner than 4 weeks following documentation of the initial response. Patients who did not qualify for a CR or PR were evaluated as having either stable disease (SD) or progressive disease (PD).

The rate of CR, duration of overall objective response, progression-free survival (PFS), and overall survival were the secondary measures of antitumor activity. Duration of response was defined as the time interval measured in days between the first date on which the criteria for objective response were met and the first date on which objective progression was documented. PFS was defined as the interval between the date of first study treatment and the first date (plus one day) on which criteria for PD or death were met.

Safety assessments were also a secondary objective. Occurrence and severity of AEs, physical examinations, weight, vital signs, ECOG performance scores, clinical laboratories (hematology, chemistry, and coagulation), and urinalysis were collected. ECGs were recorded at baseline, end of treatment and at the 30-day follow-up visit.

\section{Statistical Analysis}

Continuous variables were summarized descriptively using mean, standard deviation (SD), median, minimum (min), and maximum ( $\max$ ). Categorical variables were summarized descriptively through the use of number and percent. All statistical analyses were carried out using SAS ${ }^{\circledast}$ version 8.2 running on Windows XP.

The evaluable population $(\mathrm{N}=40)$ was defined as those patients who received at least 21 days of talabostat (i.e., $75 \%$ of the planned doses) in Cycles 1 and 2, had no more than 7 days of vomiting in the first two cycles, and had a post-baseline response assessment. The intention-to-treat (ITT) population ( $\mathrm{N}=74)$ was defined as all patients who received at least one dose of talabostat. The safety population ( $\mathrm{N}=74)$ was defined as those patients who received any dose of talabostat or cisplatin. In this study, these 2 
populations were the same. The ITT population was used in analyses of the secondary endpoints.

\section{Results}

\section{Patient Characteristics}

Initially, up to 54 evaluable patients were to be enrolled in this study, with enrollment proceeding in 2 stages. Stage 1 was to be completed after 19 evaluable patients were enrolled.

However, initial evaluation of safety revealed a high unevaluability rate related to the higher dose of cisplatin. This cisplatin dose was reduced from $100 \mathrm{mg} / \mathrm{m}^{2}$ to $75 \mathrm{mg} / \mathrm{m}^{2}$ and additional patients were placed on trial for a total of 74 patients. Forty were evaluable for response (defined as those patients who received at least 21 days of talabostat in Cycles 1 and 2). In both the ITT and Evaluable populations, the median age was 58.0 years (range, 27-79). In the ITT population, nearly all patients were white, nonHispanic (69/74 [93.2\%]). Fifty patients (67.6\%) were male. Additional demographic and baseline clinical data is presented in Table 1.

\section{Efficacy}

Six objective responses, all PRs, were recorded in the 74 patients in the ITT Population for a response rate of $8.1 \%$

Table I: Baseline demographic data and disease characteristics of enrolled patients.

\begin{tabular}{|c|c|c|}
\hline & $\begin{array}{l}\text { ITT Population } \\
(\mathrm{N}=74)\end{array}$ & $\begin{array}{c}\text { Evaluable Population } \\
\qquad(\mathrm{N}=40)\end{array}$ \\
\hline \multicolumn{3}{|l|}{ Age, yrs } \\
\hline Median (range) & $58.0(27-79)$ & $58.0(32-79)$ \\
\hline Mean (SD) & $57.6(12.79)$ & $58.9(13.08)$ \\
\hline \multicolumn{3}{|l|}{ Race, n (\%) } \\
\hline White, Non-Hispanic & $69(93.2)$ & $39(97.5)$ \\
\hline Black, Non-Hispanic & $2(2.7)$ & $\mathrm{I}(2.5)$ \\
\hline Hispanic & $2(2.7)$ & 0 \\
\hline Asian or Pacific Islander & $\mathrm{I}(\mathrm{l} .4)$ & 0 \\
\hline \multicolumn{3}{|l|}{ Gender, n (\%) } \\
\hline Male & $50(67.6)$ & $28(70.0)$ \\
\hline Female & $24(32.4)$ & $12(30.0)$ \\
\hline \multicolumn{3}{|l|}{ Tobacco use, n (\%) } \\
\hline Never & $32(43.2)$ & $14(35.0)$ \\
\hline Past & $26(35.1)$ & $17(42.5)$ \\
\hline Current & $16(21.6)$ & $9(22.5)$ \\
\hline \multicolumn{3}{|l|}{ ECOG performance status, $n$ (\%) } \\
\hline 0 & $32(43.2)$ & $20(50.0)$ \\
\hline I & $42(56.8)$ & $20(50.0)$ \\
\hline \multicolumn{3}{|l|}{ Time since initial melanoma diagnosis, months } \\
\hline Median (range) & $28.0(1-420)$ & $30.5(3-225)$ \\
\hline Mean (SD) & $50.1(66.28)$ & $45.5(45.43)$ \\
\hline \multicolumn{3}{|c|}{ Time since first diagnosis of Stage IV melanoma, months } \\
\hline Median (range) & $4.0(0-89)$ & $5.0(0-30)$ \\
\hline Mean (SD) & $9.3(15.66)$ & $7.5(7.61)$ \\
\hline \multicolumn{3}{|l|}{ Stage at original diagnosis, n (\%) } \\
\hline Stage 0 & $\mathrm{I}(\mathrm{l} .4)$ & 0 \\
\hline Stage I & $10(13.5)$ & $3(7.5)$ \\
\hline Stage II & $16(21.6)$ & $8(20.0)$ \\
\hline Stage III & $26(35.1)$ & $15(37.5)$ \\
\hline Stage IV & $18(24.3)$ & II (27.5) \\
\hline Stage unknown & $3(4.1)$ & $3(7.5)$ \\
\hline \multicolumn{3}{|l|}{ Histologic subtype, n (\%) } \\
\hline Superficial spreading melanoma & $17(23.0)$ & $7(17.5)$ \\
\hline Nodular melanoma & $30(40.5)$ & $20(50.0)$ \\
\hline Acral lentiginous melanoma & $3(4.1)$ & 0 \\
\hline Other & $24(32.4)$ & $13(32.5)$ \\
\hline \multicolumn{3}{|l|}{ Current M classification by sites of metastasesa , n (\%) } \\
\hline Mla: Distant skin, subcutaneous, or nodal metastases & $7(9.5)$ & $4(10.0)$ \\
\hline MIb: Lung metastases & $13(17.6)$ & $7(17.5)$ \\
\hline MI c: All other visceral metastases & $54(73.0)$ & $29(72.5)$ \\
\hline
\end{tabular}

ITT = intention-to-treat; SD = standard deviation; ECOG = Eastern Cooperative Oncology Group

a Per 2002 AJCC. Baseline LDH levels were used in this classification. 
$(6 / 74)$. Five of these responses were in the evaluable population, for a response rate of $12.5 \%$ (5/40). Response assessments based on RECIST criteria and are summarized in Table 2.

The most common assessment of SD was documented in $25 / 40(62.5 \%)$ of evaluable patients at cycle 3, day 1 and $13 / 40(32.5 \%)$ at Cycle 5, Day 1. The duration of stable disease in 12 evaluable patients was not maintained out to cycle 5 . For the patients who responded, the duration of the response ranged from 62 to 287 days. Table 3 presents disease assessments, prior treatments, and the response to talabostat for all patients with objective overall responses.

The estimate of median PFS using the Kaplan-Meier survival analysis algorithm for the ITT population was 92.0 days based on the investigator assessment using RECIST. Table 4 presents the overall median PFS estimate. The estimates of PFS was suggested to be greater for patients with a M1b classification and escalated dose of talabostat.

For the ITT Population, the estimate of median overall survival using the Kaplan-Meier algorithm was 230.0 days, regardless of whether patients starting a new antimelanoma therapy were censored. Table 5 presents median survival estimates for the ITT Population overall, and by $M$ classification, prior chemotherapy treatment, dose escalation with talabostat, or initial cisplatin dose. The overall survival estimates were greater for patients who did not receive prior chemotherapy (340.0 vs. 165.0 days) and for those who dose-escalated with talabostat (330.0 vs. 139.0 days). The initial cisplatin dose level did not significantly impact overall survival.

\section{Safety}

All enrolled patients who received any talabostat or cisplatin were included in the safety population $(\mathrm{N}=74)$. The majority of adverse events (AEs) (821/1071 [76.7\%]) occurred during the first 3 cycles of treatment. Forty-two patients (42/74 [56.8\%]) experienced grade 3 or grade 4 AEs, 23/74 (31.1\%) patients reported SAEs, and 14/74 (18.9\%) patients discontinued talabostat due to an AE. A summary of AEs by cycle and overall is presented in Table 6. AEs experienced by $\geq 3$ patients $(4.1 \%)$ in the Safety Population are listed in Table 7 by system organ class, with the preferred terms listed in decreasing frequency.

Ten patients (10/74 [13.5\%]) had AEs which were considered by the investigator as definitely related to talabostat. These AEs included 7 patients with events of edema (including peripheral, localized, facial, and periorbital edema, fluid retention, and edema NOS), two patients with nausea, and one incident each of rigors, performance status decreased, weight increased, myalgia, genital edema, pruritis, or peripheral cyanosis. With the exception of performance status decrease, which occurred during the extended treatment cycles (>cycle 6), these events occurred exclusively in cycles 1 and/or 2 . AEs experienced by $\geq 3$ patients by dose level of talabostat are presented in Table 8. The percentage of patients experiencing AEs were similar between dose groups in most body system organ classes.

Over a third of the patients $(27 / 74$ [36.5\%]) had AEs considered by the investigator as definitely related to cisplatin. The majority of these events involved the hematopoietic system (15 patients; 11 with neutropenia, febrile neutropenia, and/or neutrophil count decreased)

Table 2: Overall objective response rate of patients at cycle 3 and maintained to cycle 5 or end of treatment.

\begin{tabular}{lcc}
\hline $\begin{array}{c}\text { Timepoint } \\
\text { Overall response to treatment }{ }^{\mathrm{a}}\end{array}$ & $\begin{array}{c}\text { ITT Population } \\
(\mathrm{N}=74)\end{array}$ & $\begin{array}{c}\text { Evaluable Population } \\
(\mathrm{N}=40)\end{array}$ \\
\hline $\begin{array}{l}\text { Cycle 3, Day I } \\
\text { CR }\end{array}$ & 0 & 0 \\
PR & $3(4.1)^{\mathrm{b}}$ & $3(7.5)$ \\
SD & $34(45.9)$ & $25(62.5)$ \\
Cycle 5, Day I & & 0 \\
CR & 0 & $3(7.5)$ \\
PR & $3(4.1)$ & $13(32.5)$ \\
SD & $16(21.6)$ & \\
End of treatment or early termination & & $1(2.5)$ \\
CR & 0 & $7(17.5)$ \\
PR & $2(2.7)$ & $10(13.5)$ \\
SD & & \\
\hline
\end{tabular}

ITT = intention-to-treat; $C R$ = complete response; $P R=$ partial response; $S D$ = stable disease; $P D=$ progressive disease a Response is based on the investigator's assessment using RECIST. b N (\%). 
Table 3: Objective response to talabostat.

\begin{tabular}{|c|c|c|c|c|c|c|}
\hline $\begin{array}{c}\text { Age/Sex } \\
\text { (Patient No.) }\end{array}$ & $\begin{array}{l}\text { M classification } \\
\text { at enrollment }\end{array}$ & $\begin{array}{l}\text { Metastatic sites at } \\
\text { enrollment }\end{array}$ & $\begin{array}{c}\text { Prior Tx for } \\
\text { Stage IV disease }\end{array}$ & $\begin{array}{l}\text { Best response } \\
\text { to prior } \mathrm{Tx}\end{array}$ & $\begin{array}{c}\text { Response to } \\
\text { talabostat }\end{array}$ & $\begin{array}{c}\text { Duration of } \\
\text { Response (days) }\end{array}$ \\
\hline $\begin{array}{c}54 / F \\
(0 I-003)\end{array}$ & MIb & Skin, lung & $\begin{array}{l}\text { Tumor peptide } \\
\text { heat shock } \\
\text { (Vitespen) }\end{array}$ & PD & PR & $|5|$ \\
\hline $\begin{array}{c}46 / M \\
(04-002)\end{array}$ & MIb & Lung & Sargramostim & PD & PR & 62 \\
\hline $\begin{array}{c}63 / M \\
(04-003)\end{array}$ & MIb & Lung & None & NA & PR & 287 \\
\hline $\begin{array}{c}6 \mathrm{I} / \mathrm{F} \\
(06-00 \mathrm{I})\end{array}$ & MIc & $\begin{array}{l}\text { Subcutaneous tissue, } \\
\text { stomach, lymph } \\
\text { node(s), visceral }\end{array}$ & $\begin{array}{l}\text { Temozolomide, } \\
\text { thalidomide }\end{array}$ & SD & PR & Unknownc \\
\hline $\begin{array}{c}53 / M \\
(09-014)\end{array}$ & Mlc & $\begin{array}{l}\text { Regional lymph } \\
\text { node(s), liver }\end{array}$ & None & NA & PR & 176 \\
\hline $\begin{array}{c}58 / F \\
(12-003)\end{array}$ & Mlc & $\begin{array}{l}\text { Lymph nodes beyond } \\
\text { regional, lung, } \\
\text { abdominal wall }\end{array}$ & None & NA & $P R$ & $|4|$ \\
\hline
\end{tabular}

$T x=$ treatment; $P D=$ progressive disease; $P R=$ partial response; $N A=$ not applicable; $S D=$ stable disease

a Mla: Distant skin, subcutaneous, or nodal metastases; MIb: Lung metastases; MIc: all other visceral metastases. Baseline LDH levels were also used in this classification.

b Includes chemotherapy and/or immunotherapy.

c The patient was lost to follow-up.

or gastrointestinal disorders (14 patients; 11 with vomiting NOS). Of the 4 most common AEs experienced by patients in this study, the majority were considered possibly, probably, or definitely related to cisplatin $(43 / 44$ events of nausea, 35/38 vomiting, 32/37 fatigue, and 27/ 29 events of anemia). A summary of AEs by severity and by relationship to talabostat or cisplatin is presented in Table 9 by cycle and overall.
The number and percent of patients with AEs were also analyzed by the initial cisplatin dose the patient received $\left(100 \mathrm{mg} / \mathrm{m}^{2}\right.$ or $75 \mathrm{mg} / \mathrm{m}^{2}$ ). Patients whose initial cisplatin dose was $75 \mathrm{mg} / \mathrm{m}^{2}$ experienced fewer AEs in the hematopoietic system (18/39 [46.2\%]) as well as in the organ system category of AE's (13/39 [33.3\%]), compared to those who received the $100 \mathrm{mg} / \mathrm{m}^{2}$ dose (23/35 [65.7\%] and 19/35 [54.3\%], respectively).

Table 4: Progression free survival

\begin{tabular}{|c|c|}
\hline & $\begin{array}{l}\text {-----Time to PD or Death (days) }{ }^{\mathrm{a}} \text {--.----- } \\
\text { Median }(95 \% \mathrm{Cl}) \text {, days }\end{array}$ \\
\hline Overall PFS $(\mathbf{N}=74)^{b}$ & $92.0(79.0,126.0)$ \\
\hline \multicolumn{2}{|l|}{ Exploratory Analyses } \\
\hline \multicolumn{2}{|l|}{ PFS by: } \\
\hline \multicolumn{2}{|l|}{ M classification } \\
\hline MIa $(n=7)$ & $85.0(40.0,270.0)$ \\
\hline$M I b(n=13)$ & $135.0(103.0,205.0)$ \\
\hline MIc $(n=54)$ & $85.0(68.0,110.0)$ \\
\hline \multicolumn{2}{|l|}{ Prior chemotherapy } \\
\hline With $(n=40)$ & $89.0(78.0,143.0)$ \\
\hline Without $(n=34)$ & $97.0(42.0,180.0)$ \\
\hline \multicolumn{2}{|c|}{ Dose escalation of talabostat } \\
\hline With $(n=44)$ & | $35.0(89.0, \mid 70.0)$ \\
\hline Without $(n=30)$ & $79.0(42.0,109.0)$ \\
\hline \multicolumn{2}{|l|}{ Initial cisplatin dose } \\
\hline $100 \mathrm{mg} / \mathrm{m}^{2}(\mathrm{n}=35)$ & $80.0(44.0,103.0)$ \\
\hline $75 \mathrm{mg} / \mathrm{m}^{2}(\mathrm{n}=39)$ & $126.0(85.0,169.0)$ \\
\hline
\end{tabular}

$\mathrm{PD}=$ progressive disease; $\mathrm{PFS}=$ progression-free survival; $\mathrm{Cl}=$ confidence interval a Response is based on the investigator's assessment.

b ITT population. 
Table 5: Overall survival

\begin{tabular}{|c|c|c|}
\hline & \multicolumn{2}{|c|}{ - } \\
\hline & $\begin{array}{l}\text { Analysis with censoring of patients who began } \\
\text { a new therapy }\end{array}$ & $\begin{array}{c}\text { Analysis without censoring of patients who } \\
\text { began a new therapy }\end{array}$ \\
\hline & Median $(95 \% \mathrm{Cl})$, days ${ }^{c}$ & Median $(95 \% \mathrm{Cl})$, days ${ }^{c}$ \\
\hline Overall Survival $(\mathbf{N}=74)$ & $230.0(143.0,401.0)$ & $230.0(148.0,330.0)$ \\
\hline \multicolumn{3}{|l|}{ Exploratory Analyses } \\
\hline \multicolumn{3}{|l|}{ Overall survival by: } \\
\hline \multicolumn{3}{|l|}{$M$ classification } \\
\hline Mla $(n=7)$ & NE $(270.0, N E)$ & $340.0(270.0, \mathrm{NE})$ \\
\hline$M I b(n=13)$ & NE $(230.0, N E)$ & NE \\
\hline Mlc $(n=54)$ & $148.0(\mid 16.0,297.0)$ & $148.0(\mid 17.0,239.0)$ \\
\hline \multicolumn{3}{|l|}{ Prior chemotherapy } \\
\hline With $(n=40)$ & $165.0(\mid 18.0,297.0)$ & $165.0(143.0,297.0)$ \\
\hline Without $(n=34)$ & $401.0(138.0, \mathrm{NE})$ & $340.0(139.0, \mathrm{NE})$ \\
\hline \multicolumn{3}{|l|}{ Dose escalation of talabostat } \\
\hline With $(n=44)$ & $330.0(153.0, \mathrm{NE})$ & $330.0(165.0, \mathrm{NE})$ \\
\hline Without $(n=30)$ & $139.0(81.0,270.0)$ & $139.0(81.0,230.0)$ \\
\hline \multicolumn{3}{|l|}{ Initial cisplatin dose } \\
\hline $100 \mathrm{mg} / \mathrm{m}^{2}(\mathrm{n}=35)$ & $230.0(109.0, \mathrm{NE})$ & $239.0(116.0,401.0)$ \\
\hline $75 \mathrm{mg} / \mathrm{m}^{2}(\mathrm{n}=39)$ & 209.0 (I48.0, NE) & $209.0(148.0,340.0)$ \\
\hline
\end{tabular}

$\mathrm{Cl}=$ confidence interval; $\mathrm{NE}=$ non-estimable

a Patients not dying had their survival time censored on the last date of known contact. Patients who began another anti-melanoma therapy were censored on the start date of the new anti-melanoma treatment.

b Patients not dying had their survival time censored on the last date of known contact. Patients who began another anti-melanoma therapy were not censored because of the new therapy.

c In many cases, there was insufficient information to calculate the median or the upper limit for the $\mathrm{Cl}$ for these data.

d ITT population.

Twenty-three patients $(23 / 74[31.1 \%])$ reported SAEs; 15 of these patients were receiving talabostat at $300 \mathrm{mcg}$ BID at the time of their event and 8 had dose-escalated to 400 mcg BID. The incidence of SAEs was relatively constant over the 6 cycles of treatment, ranging from 5.3 to $13.1 \%$ of patients in a given cycle experiencing an SAE. There were no SAEs reported in the extended treatment phase of the study (> Cycle 6).
Eleven SAEs were reported in more than one patient: dehydration was reported in 6 patients; vomiting, dizziness, acute renal failure, dyspnea, and hypotension NOS were each reported in 3 patients; and 2 patients each experienced nausea, fatigue, pain NOS, renal failure NOS, or orthostatic hypotension. One patient experienced SAEs of peripheral edema, facial edema, and peripheral cyanosis that were considered definitely related to talabostat. A sec-

Table 6: Adverse events.

\begin{tabular}{|c|c|c|c|c|c|c|c|c|}
\hline & $\begin{array}{l}\text { Cycle I } \\
(n=74)^{a}\end{array}$ & $\begin{array}{l}\text { Cycle } 2 \\
(n=61)\end{array}$ & $\begin{array}{l}\text { Cycle } 3 \\
(n=38)\end{array}$ & $\begin{array}{l}\text { Cycle } 4 \\
(n=32)\end{array}$ & $\begin{array}{l}\text { Cycle } 5 \\
(n=19)\end{array}$ & $\begin{array}{l}\text { Cycle } 6 \\
(n=18)\end{array}$ & $\begin{array}{l}>\text { Cycle } 6 \\
(n=15)\end{array}$ & $\begin{array}{l}\text { Overall } \\
(N=74)\end{array}$ \\
\hline Number of AEs & 448 & 245 & 128 & 79 & 38 & 28 & 105 & 1071 \\
\hline No AEs & $7(9.5)^{b}$ & $7(\mathrm{I} I .5)$ & $7(18.4)$ & II (34.4) & $7(36.8)$ & $6(33.3)$ & I (6.7) & $\mathrm{I}(\mathrm{l} .4)$ \\
\hline$\geq I A E$ & $67(90.5)$ & $54(88.5)$ & $31(81.6)$ & $21(65.6)$ & $12(63.2)$ & $12(66.7)$ & $14(93.3)$ & $73(98.6)$ \\
\hline $\begin{array}{l}\geq \text { IPossibly, probably, or definitely talabostat-related } \\
\text { AEs }\end{array}$ & $50(67.6)$ & $37(60.7)$ & $14(36.8)$ & II (34.4) & $10(52.6)$ & $10(55.6)$ & $9(60.0)$ & $59(79.7)$ \\
\hline$\geq 1$ Grade 3 or $4 \mathrm{AEs}$ & $15(20.3)$ & II (18.0) & $10(26.3)$ & $6(18.8)$ & $4(2 I .1)$ & $2(11.1)$ & $3(20.0)$ & $42(56.8)$ \\
\hline Discontinued talabostat due to $\geq \mathrm{I} A E$ & $8(10.8)$ & $I(1.6)$ & 0 & $I(3.1)$ & I (5.3) & 0 & $3(20.0)$ & $14(18.9)$ \\
\hline$\geq I S A E$ & $9(12.2)$ & $8(\mid 3.1)$ & $3(7.9)$ & $2(6.3)$ & I (5.3) & I (5.6) & 0 & $23(31.1)$ \\
\hline Deaths & $10(13.5)$ & $12(19.7)$ & $6(15.8)$ & $5(15.6)$ & $\mathrm{I}(5.3)$ & $\mathrm{I}(5.6)$ & $4(26.7)$ & $39(52.7)$ \\
\hline
\end{tabular}

$\mathrm{AE}=$ adverse event; $\mathrm{SAE}=$ serious adverse event

a Safety population, $\mathrm{n}=74$.

b $\mathrm{N}(\%)$ of patients. 
Table 7: Adverse events in $\geq 3$ patients overall by system organ class and preferred term events.

\begin{tabular}{|c|c|c|c|c|c|c|c|c|}
\hline $\begin{array}{l}\text { System Organ Class } \\
\text { Preferred Term }\end{array}$ & $\begin{array}{l}\text { Cycle I } \\
(n=74)^{b}\end{array}$ & $\begin{array}{l}\text { Cycle } 2 \\
(n=61)\end{array}$ & $\begin{array}{l}\text { Cycle 3 } \\
(n=38)\end{array}$ & $\begin{array}{l}\text { Cycle } 4 \\
(n=32)\end{array}$ & $\begin{array}{l}\text { Cycle } 5 \\
(n=19)\end{array}$ & $\begin{array}{l}\text { Cycle 6 } \\
(n=18)\end{array}$ & $\begin{array}{l}>\text { Cycle } 6 \\
(n=15)\end{array}$ & $\begin{array}{l}\text { Overall } \\
(N=74)\end{array}$ \\
\hline Blood and Lymphatic System Disorders & $24(32.4)^{c}$ & $17(27.9)$ & I I (28.9) & $9(28.1)$ & 5 (26.3) & $3(16.7)$ & $4(26.7)$ & $41(55.4)$ \\
\hline Anaemiad $^{d}$ & $14(18.9)$ & $9(14.8)$ & $6(15.8)$ & $3(9.4)$ & I (5.3) & $\mathrm{I}(5.6)$ & $2(13.3)$ & $29(39.2)$ \\
\hline Thrombocytopeniae & $8(10.8)$ & $3(4.9)$ & $3(7.9)$ & $6(18.8)$ & $5(26.3)$ & $2(I I . I)$ & $4(26.7)$ & $18(24.3)$ \\
\hline Neutropeniaf & $8(10.8)$ & $3(4.9)$ & $6(15.8)$ & I (3.I) & $3(15.8)$ & 0 & $2(13.3)$ & $14(18.9)$ \\
\hline Leukopeniag & $\mathrm{I}(1.4)$ & $2(3.3)$ & $3(7.9)$ & $I(3.1)$ & $\mathrm{I}(5.3)$ & 0 & I (6.7) & $7(9.5)$ \\
\hline Cardiac Disorders & $2(2.7)$ & $2(3.3)$ & 0 & 0 & I (5.3) & 0 & 0 & $5(6.8)$ \\
\hline Palpitations & $2(2.7)$ & 0 & 0 & 0 & I (5.3) & 0 & 0 & $3(4.1)$ \\
\hline Ear and Labyrinth Disorders & I I (14.9) & $4(6.6)$ & 5 (13.2) & 0 & I (5.3) & 0 & I (6.7) & $19(25.7)$ \\
\hline Tinnitus & $8(10.8)$ & $3(4.9)$ & $4(10.5)$ & 0 & 0 & 0 & 0 & $13(17.6)$ \\
\hline Hypoacusis & $3(4.1)$ & $2(3.3)$ & $2(5.3)$ & 0 & 0 & 0 & 0 & $5(6.8)$ \\
\hline Eye Disorders & $4(5.4)$ & $3(4.9)$ & 5 (13.2) & I (3.1) & $2(10.5)$ & 0 & $3(20.0)$ & $13(17.6)$ \\
\hline Vision blurred & 0 & $2(3.3)$ & I (2.6) & $\mathrm{I}(3.1)$ & I (5.3) & 0 & I (6.7) & $6(8.1)$ \\
\hline
\end{tabular}

a System organ classes are presented alphabetically and preferred terms are listed by decreasing frequency and ordered by the "Overall" column. A patient with multiple occurrences of an $A E$ is counted only once for the AE category. A patient who reported $\geq 2$ AEs with different preferred terms within the same system organ class was counted only once in the system organ class total. AEs that do not meet frequency criteria for inclusion in the table are included in the system organ class totals.

b Safety population, $\mathrm{n}=74$.

c $\mathrm{N}(\%)$ of patients.

d Includes terms: anaemia, anaemia NOS, red blood cell count decreased, and haemoglobin decreased.

e Includes terms: thrombocytopenia and platelet count decreased

f Includes terms: neutropenia and neutrophil count decreased.

g Includes terms: leukopenia and leukopenia NOS.

ond patient experienced SAEs of anasarca, dehydration, and renal failure NOS, all considered probably related to talabostat. Both patients recovered from the events.

The incidence of specific hematologic events was analyzed (Table 6). Few patients experienced AEs of grade 4 neutropenia, febrile neutropenia, grade 3 or grade 4 anemia, or infections requiring hospitalization. Grade 3/4 neutropenia and thrombocytopenia was observed in $18.9 \%$ and $24.3 \%$ of patients, respectively. No trends for an effect of talabostat on these hematologic parameters were evident in this study.

Overall, there were a total of $39(39 / 74$ [52.7\%]) deaths in this study, the majority of which $(36 / 39)$ were due to PD. Eleven patients died within 30 days of receiving talabostat: 5 patients died due to $\mathrm{PD}$, melanoma was the cause of death for 3 additional patients, one patient had a myocardial infarction, and 2 patients died of organ failure (end organ failure and renal failure). Hepatic/renal failure also contributed to the death of one patient with metastatic melanoma. The death from renal failure was considered possibly related to both talabostat and cisplatin, and the myocardial infarction was considered unlikely related to talabostat but possibly related to cisplatin. The other deaths were considered not related or unlikely to be related to the study medications.

Eighteen patients $(18 / 74[24.3 \%])$ experienced $\geq 1 \mathrm{AE}$ that led to discontinuation of study medication. Fourteen of these patients (14/74 [18.9\%]) discontinued talabostat
(6 patients discontinued talabostat only and 8 patients discontinued both talabostat and cisplatin); 4 patients discontinued cisplatin, but continued receiving talabostat.

\section{Discussion}

Metastatic melanoma carries a grave prognosis, with overall survival of less than 12 months despite significant efforts to develop novel therapeutic agents. Talabostat is an orally available dipeptidyl peptidase inhibitor with immunogenic properties that has demonstrated therapeutic effects in a mouse model of melanoma [28].

The results from this phase II trial of talabostat and cisplatin in metastatic melanoma failed to show significant improvement over currently available treatments. Of 74 patients in the ITT population, those who received a single dose of talabostat, six objective responses, all PRs, were recorded for a response rate of $8.1 \%(6 / 74)$. Five of these responses were also in the evaluable population (those who did not progress within the first 21 days of treatment), yielding a response rate of $12.5 \%(5 / 40)$ for this population. The duration of the response ranged from 62 to 287 days. By the end of treatment or extended treatment, however, most evaluable patients were reported to have PD.

The estimate of median PFS using the Kaplan-Meier survival analysis algorithm for the ITT population was 92.0 days, based on the investigator assessment using RECIST criteria. The estimates of PFS appeared greater for patients 
Table 8: Adverse events in $\geq \mathbf{3}$ patients by talabostat dose level.

\begin{tabular}{|c|c|c|c|}
\hline \multirow[b]{2}{*}{ System Organ Class ${ }^{a}$} & \multicolumn{3}{|c|}{----Talabostat Dose BID--- } \\
\hline & $300 \mathrm{mcg}$ & $400 \mathrm{mcg}$ & Overall \\
\hline Preferred term & $(n=74)^{b}$ & $(n=44)$ & $(\mathrm{N}=74)$ \\
\hline Blood and Lymphatic System Disorders & $32(43.2)^{c}$ & $19(43.2)$ & $4 I(55.4)$ \\
\hline Anaemiad $^{d}$ & $20(27.0)$ & II $(25.0)$ & $29(39.2)$ \\
\hline Thrombocytopeniae & $13(17.6)$ & $8(18.2)$ & $18(24.3)$ \\
\hline Neutropenia ${ }^{f}$ & $12(16.2)$ & $5(11.4)$ & 14 (18.9) \\
\hline Leukopeniag & $4(5.4)$ & $4(9.1)$ & $7(9.5)$ \\
\hline Cardiac Disorders & $2(2.7)$ & $3(6.8)$ & $5(6.8)$ \\
\hline Palpitations & $2(2.7)$ & $\mathrm{I}(2.3)$ & $3(4.1)$ \\
\hline Ear and Labyrinth Disorders & $15(20.3)$ & $5(11.4)$ & $19(25.7)$ \\
\hline Tinnitus & $10(13.5)$ & $4(9.1)$ & $13(17.6)$ \\
\hline Hypoacusis & $4(5.4)$ & I (2.3) & $5(6.8)$ \\
\hline Eye Disorders & $9(12.2)$ & 7 (15.9) & $13(17.6)$ \\
\hline Vision blurred & $2(2.7)$ & $4(9.1)$ & $6(8.1)$ \\
\hline Gastrointestinal Disorders & $54(73.0)$ & $21(47.7)$ & $58(78.4)$ \\
\hline Nausea & $38(5 \mathrm{I} .4)$ & II (25.0) & $44(59.5)$ \\
\hline Vomiting NOS & $31(4 \mid .9)$ & $10(22.7)$ & $38(51.4)$ \\
\hline Constipation & $22(29.7)$ & $7(15.9)$ & $25(33.8)$ \\
\hline Diarrhoea NOS & $9(12.2)$ & $5(11.4)$ & $13(17.6)$ \\
\hline Abdominal pain NOS & $3(4.1)$ & $4(9.1)$ & $7(9.5)$ \\
\hline Dyspepsia & $2(2.7)$ & $3(6.8)$ & $5(6.8)$ \\
\hline Stomatitis & $\mathrm{I}(\mathrm{l} .4)$ & $2(4.5)$ & $3(4.1)$ \\
\hline
\end{tabular}

BID = twice daily

a System organ classes are presented alphabetically and preferred terms are listed by decreasing frequency and ordered by the "Overall" column. A patient with multiple occurrences of an $A E$ is counted only once for the $A E$ category. A patient who reported $\geq 2$ AEs with different preferred terms within the same system organ class was counted only once in the system organ class total. AEs that do not meet frequency criteria for inclusion in the table are included in the system organ class totals.

b Safety population, $\mathrm{n}=74$.

c N (\%) of patients.

d Includes terms: anaemia, anaemia NOS, red blood cell count decreased, and haemoglobin decreased.

e Includes terms: thrombocytopenia and platelet count decreased.

f Includes terms: neutropenia and neutrophil count decreased.

g Includes terms: leukopenia and leukopenia NOS.

with an M1b classification and escalated dose of talabostat. The estimate of median overall survival was 230.0 days, regardless of whether patients starting a new antimelanoma treatment were censored. Overall survival estimates were greater for patients who dose-escalated and for patients with no prior chemotherapy.

In this population of patients with advanced disease, $56 /$ $74(75.7 \%)$ patients were unable to complete 6 cycles (18 weeks) of talabostat, primarily due to PD. There were 15 patients who completed 6 cycles of talabostat and continued to receive additional cycles of talabostat.

Overall, the combination of talabostat and cisplatin was well tolerated compared to historical data using cisplatin alone. The most frequent AEs were nausea, vomiting, fatigue, anemia, edema, and constipation. Most of these events were considered related to cisplatin. The majority of patients experienced either a grade 2 or a grade $3 \mathrm{AE}$ as their most severe event. The percentages of patients experiencing AEs and the types of AEs were similar between the groups who did and did not dose-escalate. This safety profile is consistent with phase 1 studies conducted in 120 healthy male volunteers, in which talabostat was well tolerated at single daily doses up to $2400 \mu \mathrm{g}$ and when administered as a single dose for seven days at doses up to $1800 \mu \mathrm{g}$ [30]. However, given the toxicity profile that we observed to cisplatin and a slightly higher early death rate than expected related to progressive disease, further safety assessment is necessary.

\section{Conclusion}

In conclusion, despite promising preclinical evidence, combination treatment with talabostat and cisplatin did not significantly affect disease progression in this study. Antitumor activity was observed in 5/40 (12.5\%) of eval- 
Table 9: Adverse events by severity and causality.

\begin{tabular}{|c|c|c|c|c|c|c|c|c|}
\hline & $\begin{array}{l}\text { Cycle I } \\
(n=74)^{a}\end{array}$ & $\begin{array}{l}\text { Cycle } 2 \\
(n=61)\end{array}$ & $\begin{array}{l}\text { Cycle } 3 \\
(n=38)\end{array}$ & $\begin{array}{l}\text { Cycle } 4 \\
(n=32)\end{array}$ & $\begin{array}{l}\text { Cycle } 5 \\
(n=19)\end{array}$ & $\begin{array}{l}\text { Cycle } 6 \\
(n=18)\end{array}$ & $\begin{array}{c}>\text { Cycle } 6 \\
(n=15)\end{array}$ & $\begin{array}{l}\text { Overall } \\
(N=74)\end{array}$ \\
\hline \multicolumn{9}{|l|}{ Severity } \\
\hline Grade I & $19(25.7)^{\mathrm{b}}$ & I3 (2I.3) & $8(2||)$. & $8(25.0)$ & $6(31.6)$ & $8(44.4)$ & $8(53.3)$ & $6(8.1)$ \\
\hline Grade 2 & $33(44.6)$ & $30(49.2)$ & $13(34.2)$ & $7(21.9)$ & $2(10.5)$ & 2 (II.I) & $3(20.0)$ & $25(33.8)$ \\
\hline Grade 3 & $10(13.5)$ & $9(14.8)$ & $8(2 \mathrm{l} . \mathrm{l})$ & $4(12.5)$ & $2(10.5)$ & $2(11.1)$ & $2(13.3)$ & $28(37.8)$ \\
\hline Grade 4 & $3(4.1)$ & 0 & I (2.6) & I (3.I) & $2(10.5)$ & 0 & I (6.7) & $8(10.8)$ \\
\hline Grade 5 & $2(2.7)$ & $2(3.3)$ & I (2.6) & I (3.I) & 0 & 0 & 0 & $6(8.1)$ \\
\hline \multicolumn{9}{|c|}{ Relationship to talabostatc } \\
\hline Not related & $6(8.1)$ & II (I8.0) & 7 (I8.4) & $5(15.6)$ & 0 & I (5.6) & $3(20.0)$ & $6(8.1)$ \\
\hline Unlikely & II (I4.9) & $6(9.8)$ & $10(26.3)$ & $5(15.6)$ & $2(10.5)$ & I (5.6) & $2(13.3)$ & $8(10.8)$ \\
\hline Possible & $33(44.6)$ & $31(50.8)$ & $9(23.7)$ & $10(31.3)$ & $8(42.1)$ & 7 (38.9) & $4(26.7)$ & 38 (5।.4) \\
\hline Probable & $10(13.5)$ & $2(3.3)$ & $4(10.5)$ & 0 & I (5.3) & $2(I I .1)$ & $3(20.0)$ & II (14.9) \\
\hline Definite & $7(9.5)$ & $4(6.6)$ & I (2.6) & I (3.I) & I (5.3) & I (5.6) & $2(13.3)$ & $10(13.5)$ \\
\hline \multicolumn{9}{|c|}{ Relationship to cisplatinc } \\
\hline Not related & $3(4.1)$ & $5(8.2)$ & $5(13.2)$ & $3(9.4)$ & I (5.3) & $2(I I . I)$ & $4(26.7)$ & $3(4.1)$ \\
\hline Unlikely & $4(5.4)$ & $5(8.2)$ & $5(13.2)$ & $2(6.3)$ & $3(15.8)$ & $2(11.1)$ & $2(13.3)$ & $2(2.7)$ \\
\hline Possible & $14(18.9)$ & II (I8.0) & $4(10.5)$ & $4(12.5)$ & I (5.3) & 2 (II.I) & I (6.7) & II (14.9) \\
\hline Probable & $28(37.8)$ & $18(29.5)$ & $9(23.7)$ & $6(18.8)$ & $5(26.3)$ & $5(27.8)$ & $5(33.3)$ & $30(40.5)$ \\
\hline Definite & $18(24.3)$ & $15(24.6)$ & $8(2 I . I)$ & $6(18.8)$ & $2(10.5)$ & I (5.6) & $2(13.3)$ & $27(36.5)$ \\
\hline
\end{tabular}

Note: A patient who reported $\geq 2$ adverse evens (AEs) with the same preferred term was counted only once for that term using the most severe incidence. A patient who reported $\geq 2 \mathrm{AEs}$ with different preferred terms within the same system organ class was counted only once in the system organ class total using the most severe incidence. A patient who reported $\geq 2 \mathrm{AEs}$ with different same system organ class was counted only once in the total using the most severe incidence.

a Safety population, $n=74$.

b $\mathrm{N}(\%)$ of patients.

c As determined by the investigator.

uable patients, suggesting the possibility of clinical benefit in a subset of melanoma patients. Based on its low toxicity profile, additional research may be warranted to investigate the potentiating antitumor effects of talabostat on other chemotherapeutic and biologic agents, perhaps in patients with earlier stage disease.

It is unclear if the antitumor activity of talabostat as seen in pre-clinical models involves the induction of immunologically active cytokines and chemokines thereby mediating an immune response or inhibition of tissue remodeling via FAP. No clinical assessment of talabostat in FAP-expressive tumors has as yet been performed. Although clinical development of talabostat has focused on the immune-mediated activity, further assessment of talabostat in patients with FAP-expressive cancers may be worthwhile.

\section{Competing interests}

The authors declare that they have no competing interests.

\section{Authors' contributions}

JN, BJ and MU established the protocol design. CCC, NS, JS, SPA, SJO, GF, ACP and JN were clinical investigators who carried out the study. BJ carried out the immunoassays and the molecular genetic studies. RME and JM drafted the manuscript. All authors read and approved the final manuscript.

\section{Acknowledgements}

The authors would like to thank Drs. Barry Berman and Paolo Paciucci for their work in recruitment, enrollment, and treatment of study participants. The authors would also like to acknowledge Brenda Marr and Susan Mill for their competent and knowledgeable assistance in the preparation of this manuscript.

\section{References}

I. Legha SS, Ring S, Papadopoulos N, Plager C, Chawla S, Benjamin R: A prospective evaluation of a triple-drug regimen containing cisplatin, vinblastine, and dacarbazine (CVD) for metastatic melanoma. Cancer 2029, 64:2024-1989.

2. McClay EF, Mastrangelo MJ, Berd D, Bellet RE: Effective combination chemo/hormonal therapy for malignant melanoma: experience with three consecutive trials. Int J Cancer 1992, 50:553-556.

3. Margolin KA, Liu PY, Flaherty LE, Sosman JA, Walker MJ, Smith JW 3rd, Fletcher WS, Weiss GR, Unger JM, Sondak VK: Phase II study of carmustine, dacarbazine, cisplatin, and tamoxifen in advanced melanoma: a Southwest Oncology Group study. J Clin Oncol 1998, 16:664-669.

4. Creagan ET, Suman VJ, Dalton RJ, Pitot HC, Long HJ, Veeder MH, Vukov AM, Rowland KM, Krook JE, Michalak JC: Phase III clinical trial of the combination of cisplatin, dacarbazine, and carmustine with or without tamoxifen in patients with advanced malignant melanoma. J Clin Oncol 1999, 17:1884-1890.

5. Falkson Cl, Ibrahim J, Kirkwood JM, Coates AS, Atkins MB, Blum RH: Phase III trial of dacarbazine versus dacarbazine with interferon alpha-2b versus dacarbazine with tamoxifen versus dacarbazine with interferon alpha-2b and tamoxifen in patients with metastatic malignant melanoma: an Eastern Cooperative Oncology Group study. J Clin Oncol 1998, 16:1743-175I.

6. Keilholz U, Goey SH, Punt CJ, Proebstle TM, Salzmann R, Scheibenbogen $C$, Schadendorf $D$, Liénard D, Enk A, Dummer R, Hantich B, Geueke AM, Eggermont AM: Interferon alfa-2a and interleukin- 
2 with or without cisplatin in metastatic melanoma: a randomized trial of the European Organization for Research and Treatment of Cancer Melanoma Cooperative Group. J Clin Oncol 1997, 15:2579-2588.

7. Rosenberg SA, Yang JC, Schwartzentruber DJ, Hwu P, Marincola FM, Topalian SL, Seipp CA, Einhorn JH, White DE, Steinberg SM: Prospective randomized trial of the treatment of patients with metastatic melanoma using chemotherapy with cisplatin, dacarbazine, and tamoxifen alone or in combination with interleukin-2 and interferon alfa-2b. J Clin Oncol 1999, 17:968-975.

8. Ridolfi R, Chiarion-Sileni V, Guida M, Romanini A, Labianca R, Freschi A, Lo Re G, Nortilli R, Brugnara S, Vitali P, Nanni O, Italian Melanoma Intergroup: Cisplatin, dacarbazine with or without subcutaneous interleukin-2, and interferon alpha-2b in advanced melanoma outpatients: results from an Italian multicenter phase III randomized clinical trial. J Clin Oncol 2002, 20:1600-1607.

9. Keilholz U, Punt CJ, Gore M, Kruit W, Patel P, Lienard D, Thomas J, Proebstle TM, Schmittel A, Schadendorf D, Velu T, Negrier S, Kleeberg U, Lehman F, Suciu S, Eggermont AM: Dacarbazine, cisplatin, and interferon-alfa-2b with or without interleukin-2 in metastatic melanoma: a randomized phase III trial (I895I) of the European Organisation for Research and Treatment of Cancer Melanoma Group. J Clin Oncol 2005, 23:6747-6755.

10. Del Vecchio M, Bajetta E, Vitali M, Gattinoni L, Santinami M, Daponte A, Sertoli MR, Queirolo P, Bernengo MG, Cascinelli N: Multicentre phase III randomized trial of cisplatin, vindesine, and dacarbzine (CVD) versus CVD plus subcutaneous (sc) interleukin2 (IL-2) and interferon-alpha $2 b$ (IFN) in metastatic melanoma patients (abstract 2489). Proc Am Soc Clin Oncol 2003, 22:709a.

II. Atkins MB, Lee S, Flaherty LE, Sosman JA, Sondak VK, Kirkwood JM: A prospective randomized phase III trial of concurrent biochemotherapy (BCT) with cisplatin, vinblastine, dacarbazine (CVD), IL-2 and interferon alpha-2b (IFN) versus CVD alone in patients with metastatic melanoma (E3695): An ECOGcoordinated intergroup trial (abstr 2847). Proc Am Soc Clin Oncol 2003:22.

12. Sasse AD, Sasse EC, Clark LG, Ulloa L, Clark OA: Chemoimmunotherapy versus chemotherapy for metastatic malignant melanoma. Cochrane Database Syst Rev 2007, I:CD0054I3.

13. Ives NJ, Stowe RL, Lorigan P, Wheatley K: Chemotherapy compared with biochemotherapy for the treatment of metastatic melanoma: a meta-analysis of 18 trials involving 2,62 I patients. J Clin Oncol 2007, 25:5426-5434.

14. Hill GJ 2nd, Krementz ET, Hill HZ: Dimethyl triazeno imidazole carboxamide and combination therapy for melanoma. IV. Late results after complete response to chemotherapy (Central Oncology Group protocols 7I3I, and 7I3IA). Cancer 7|30, 53: | 299- I305.

15. Middleton MR, Grob J], Aaronson N, Fierlbeck G, Tilgen W, Seiter S, Gore M, Aamdal S, Cebon J, Coates A, Dreno B, Henz M, Schadendorf D, Kapp A, Weiss J, Fraass U, Statkevich P, Muller M, Thatcher $\mathrm{N}$ : Randomized phase III study of temozolomide versus dacarbazine in the treatment of patients with advanced metastatic malignant melanoma. J Clin Oncol 2000, 18:158-166.

16. Kirkwood JK: Molecular Diagnosis, Prevention \& Therapy of Melanoma. New York: Marcel Dekker; 1997:219.

17. Avril MF, Aamdal S, Grob JJ, Hauschild A, Mohr P, Bonerandi JJ, Weichenthal M, Neuber K, Bieber T, Gilde K, Guillem Porta V, Fra J, Bonneterre J, Saïag P, Kamanabrou D, Pehamberger H, Sufliarsky J, Gonzalez Larriba JL, Scherrer A, Menu Y: Fotemustine compared with dacarbazine in patients with disseminated malignant melanoma: a phase III study. J Clin Oncol 2004, 22: I I I 8- I I25.

18. Coutts SJ, Kelly TA, Snow RJ, Kennedy CA, Barton RW, Adams J, Krolikowski DA, Freeman DM, Campbell SJ, Ksiazek JF, Bachovchin WW: Structure-activity relationships of boronic acid inhibitors of dipeptidyl peptidase IV. I. Variation of the $\mathrm{P} 2$ position of Xaa-boroPro dipeptides. J Med Chem 1996, 39:2087-2094.

19. Adams S, Jones B: Characterization of innate effector cells involved in the anti-tumor activity of talabostat (PT-100). American Association of Cancer Research (AACR) 97th Annual Meeting. Washington, DC 2006.

20. Adams S, Miller GT, Jones B: T-cell independent antitumor activity of talabostat (PT-I00) as a single agent and in com- bination with chemotherapy in mice. Abstract \#648. In American Association of Cancer Research (AACR) 96th Annual Meeting Volume 46. Anaheim, CA Proc Amer Assoc Cancer Res; 2005:648.

21. Adams S, Miller GT, Jesson MI, Watanabe T, Jones B, Wallner BP: PT100 , a small molecule dipeptidyl peptidase inhibitor, has potent antitumor effects and augments antibody-mediated cytotoxicity via a novel immune mechanism. Cancer Res 2004 , 64:547I-5480.

22. Jones B, Uprichard MJ: PT- 100 Investigator's Brochure. 2004

23. Jesson MI, McLean PA, Miller GT, Adams S, Aubin J, Jones B: Immune mechanism of action of talabostat: a dipeptidyl peptidase targeted antitumor agent (abstr. 1894). AACR Centennial Annual Meeting Proceedings, Los Angeles, CA 2007, 48:

24. Rosenblum JS, Kozarich JW: Prolyl peptidases: a serine protease subfamily with high potential for drug discovery. Curr Opin Chem Biol 2003, 7:496-504.

25. Garin-Chesa P, Old LJ, Rettig W]: Cell surface glycoprotein of reactive stromal fibroblasts as a potential antibody target in human epithelial cancers. Proc Natl Acad Sci USA 1990, 87:7235-7239.

26. Scanlan MJ, Raj BK, Calvo B, Garin-Chesa P, Sanz-Moncasi MP, Healey $\mathrm{JH}$, Old LJ, Rettig WJ: Molecular cloning of fibroblast activation protein alpha, a member of the serine protease family selectively expressed in stromal fibroblasts of epithelial cancers. Proc Natl Acad Sci USA 1994, 9 1:5657-566I.

27. Park JE, Lenter MC, Zimmermann RN, Garin-Chesa P, Old LJ, Rettig WJ: Fibroblast activation protein, a dual specificity serine protease expressed in reactive human tumor stromal fibroblasts. J Biol Chem 1999, 274:36505-365I2.

28. Cunningham CC: Talabostat. Expert Opin Investig Drugs 2007, 16:1459-1465.

29. Nemunaitis J, Vukelja SJ, Richards D, Cunningham C, Senzer N, Nugent J, Duncan H, Jones B, Haltom E, Uprichard MJ: Phase I trial of PT-I00 (PT-I00), a cytokine-inducing small molecule, following chemotherapy for solid tumor malignancy. Cancer Invest 2006, 24:553-561.

30. Uprichard MJ, Jones B: Phase I rising multiple-dose study of talabostat (PT-100) in healthy subjects. (Abstract \#4215). In American Society of Hematology (ASH), 46th Annual Meeting Volume 104. Issue II San Diego, CA: Blood; 2004:42I5.

31. Al-Katib A, Hurd DD, Raju R, Stephenson J, Giles F, Haltom E, Uprichard M): Phase I study of talabostat and rituximab in patients with indolent non-Hodgkin's lymphoma with primary resistance to or progression following rituximab. (Abstract \#1 403). In American Society of Hematology (ASH), 46th Annual Meeting Volume 104. Issue II San Diego, CA: Blood; 2004:1403.

32. Narra K, Mullins SR, Lee HO, Strzemkowski-Brun B, Magalong $K$ Christiansen VJ, McKee PA, Egleston B, Cohen SJ, Weiner LM, Meropol NJ, Cheng JD: Phase II trial of single agent Val-boroPro (Talabostat) inhibiting Fibroblast Activation Protein in patients with metastatic colorectal cancer. Cancer Biol Ther 2007, 6: 1691-1699.

33. Balch CM, Buzaid AC, Soong SJ, Atkins MB, Cascinelli N, Coit DG, Fleming ID, Gershenwald JE, Houghton A Jr, Kirkwood JM, McMasters KM, Mihm MF, Morton DL, Reintgen DS, Ross MI, Sober A, Thompson JA, Thompson JF: Final version of the American Joint Committee on Cancer staging system for cutaneous melanoma. J Clin Oncol 200I, 19:3635-3648.

\section{Pre-publication history}

The pre-publication history for this paper can be accessed here:

http://www.biomedcentral.com/1471-2407/9/263/pre pub 